\title{
The identification of possible future provincial boundaries for South Africa based on an intramax analysis of journey-to-work data
}

\author{
JH Nel* $\quad$ SC Krygsman ${ }^{\dagger} \quad$ T de Jong ${ }^{\ddagger}$ \\ Received: 12 August 2008; Revised: 24 October 2008; Accepted: 27 October 2008
}

\begin{abstract}
National census data contain information on place of residence and place of work. It is possible to combine this information and create journey-to-work flows. The process of establishing these flows are presented in this paper. The intramax method is explained and used to identify functional regions based upon these flows. Interesting applications, such as the demarcation of regions in South Africa are considered and solutions to disputed areas are put forward. The process of the creation of the current provincial boundaries are discussed. New boundaries, based on the intramax analysis of the journey-to-work data are proposed for four or five new provinces. Results compare favourably with those from a principal component and cluster analysis, which has previously been used to demarcate the South African space economy into a hierarchy of development regions.
\end{abstract}

Key words: Journey-to-work flows, provincial boundaries, intramax method, principal component analysis, functional regions, demarcation of regions.

\section{Introduction}

On 28 May 1993, the Negotiating Council of the Multiparty Negotiating Process established a fifteen-person commission to make proposals for new internal boundaries in South Africa [7]. The resulting Commission on the Demarcation/Delimitation of Regions (the CDDR) held its first meeting on 8 June 1993 and reached a decision by 31 July 1993. After six weeks, the commission more than doubled the number of provinces, from the initial four to the current nine provinces [7]. No meaningful time was allotted for public consultation, and the commissioners took as the initial draft the nine planning regions established by the Development Bank of Southern Africa between 1982 and 1988 [7]. Only one month of the CDDR's itinerary was devoted to gathering of testimony, and in reaction to broad

\footnotetext{
${ }^{*}$ Corresponding author: Department of Logistics, University of Stellenbosch, Private Bag X1, Matieland, 7602, South Africa, email: jhnel@sun.ac.za

${ }^{\dagger}$ Department of Logistics, University of Stellenbosch, Private Bag X1, 7602, Matieland, South Africa.

${ }^{\ddagger}$ Department of Human Geography and Urban and Regional Planning, Faculty of Geosciences, Utrecht University, PO Box 80115, 3508 TC, Utrecht, The Netherlands.
} 
public criticism, a further three months were allocated, beginning in August 1993. After the commission submitted its report, politicians hacked away and swapped magisterial districts in order to reach a final party agreement. From a party-political point of view, the negotiations resulted in demarcations that offered important minority parties a future base for provincial power [9].

Griggs [9] noted that these political party compromises resulted in two main problems: too many non-viable provinces, and boundary conflicts. Only Gauteng and the Western Cape provinces had thriving metropolitan regions, no former 'homelands' and had the potential in 1994 to generate enough income to finance their own administrations. He noted that most of the other provinces lack resources, infrastructure and capacity, and require central government support. Furthermore, more than fourteen years after the final provincial map was produced by multiparty negotiations, there were still eight or more active disputes. Griggs [9] proposed increased public participation by referenda as a way of resolving many of the issues.

Boundaries should be drawn so as to minimise the splitting of communities. South Africa's current spatial organisation and delineation are characterised by internal conflicts. Figure 1 shows, on a national level, the disputed areas after the 1993 delineation of provincial boundaries. Ramutsindela and Simon [19] described the process of negotiating between the provinces in the time period after 1993 as "horse-trading." Northern Province (currently Limpopo Province), for example, demanded that the towns of Groblersdal and Marble Hall, which are part of Mpumalanga, be transferred to the Northern Province to compensate for relinquishing Bushbuckridge. On the other hand, the people of Bushbuckridge have been campaigning for years to be incorporated into Mpumalanga and not Limpopo Province. While belonging to Limpopo Province, research has shown that many (95-98\%) of the residents prefer incorporation into Mpumalanga, with their reasons advanced being geographical proximity and economic ties. Residents argue that this is where they work and undertake their shopping [19].

According to Smith [21], the former chairperson of the ANC, Mosiuoa Lekota, became the most senior member of the party to date to suggest that a reduction in number from the current nine provinces should be considered seriously. According to Ngalwa [18] a discussion document, which moots a four or five province option, was drafted and circulated in government during 2007. Some ministers in the previous cabinet, including Finance Minister Trevor Manuel, Defence Minister Mosiuoa Lekota and Minister Sydney Mufamadi have publicly suggested that the number of provinces should be reduced. They also requested that proper research should be conducted to review the performance of the provincial system before deciding on their future.

It is clear that the process of demarcation cannot be examined without taking political motives into consideration, whilst the needs of people living and working in the provinces should also be considered. Functional regions based on activities of households and businesses are the people's way of deciding to which areas they belong. 


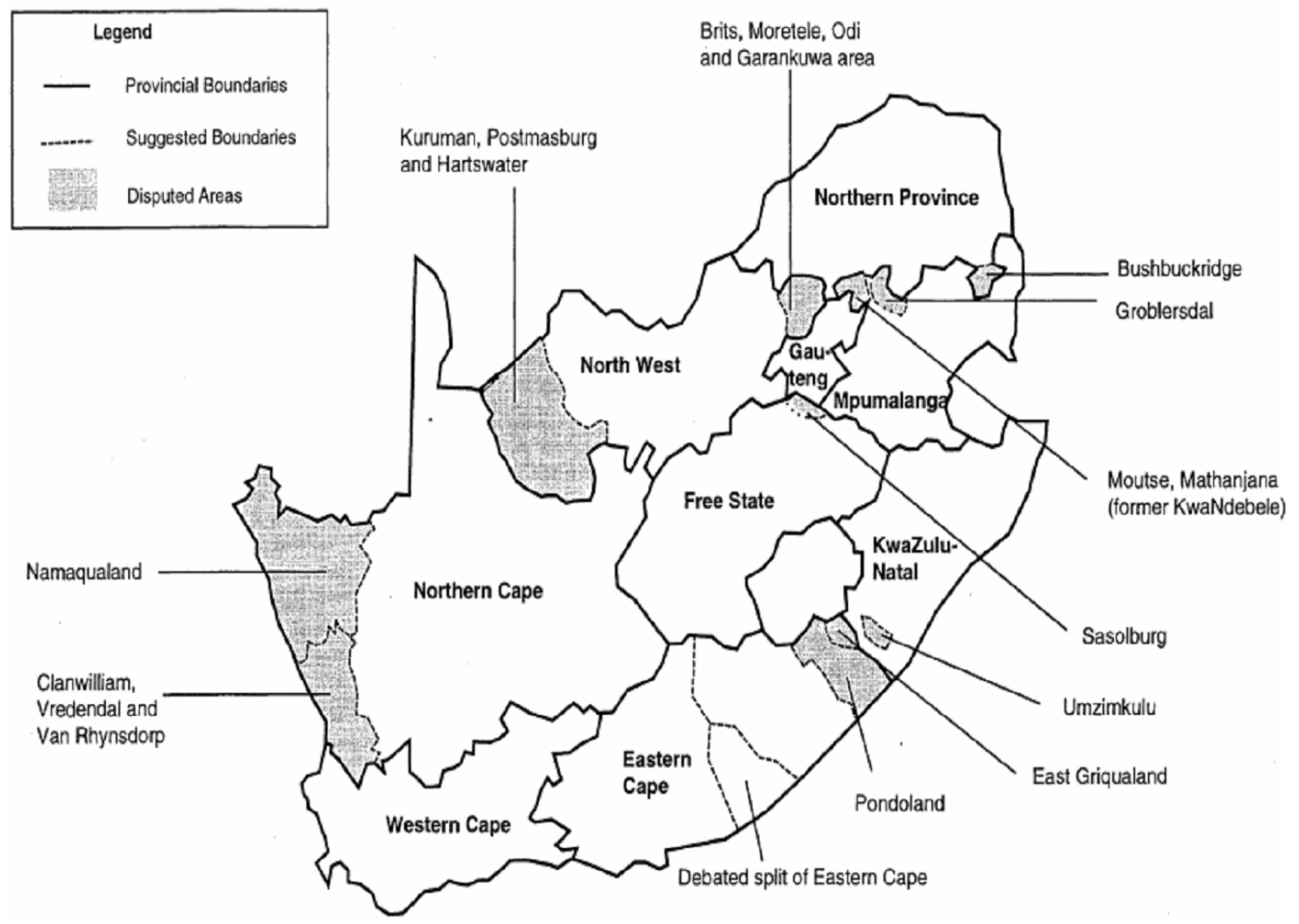

Figure 1: Disputed areas after the 1993 delimitation of provincial boundaries [19]. (Original source: Saturday Weekend Argus, 13-14 January, 1996, p20.)

\section{Functional regions}

The concept of a functional region or functional area may be described in many ways. Feldman et al. [4] described it as an area defined by business and economic activities rather than by administrative or historic boundaries. A functional region was also defined by Brown and Holmes [1] as an area or locational entity which enjoys more interaction or connection within its boundaries than with outside areas.

Functional regions may also be seen as areas in which the businesses concerned recruit most of their labour force. The quality of functional region demarcation has a strong influence on both productivity and prosperity. The functional region is a phenomenon arising exclusively from human activity, and is best described as a community of interests. In respect of human activity, specific reference is paid to transport, work and residential choice and therefore functional regions are a spatial manifestation of social organisation. Functional regions represent the day-to-day regions in people's lives, i.e. they are created by the various choices and decisions of individual people and enterprises.

Feldman et al. [4] noted that the best-established technique for a functional approach to area grouping is to identify boundaries across which relatively few people commute. Mitchell et al. [17] reasoned that journey-to-work data provide information about the interaction between spatial units and are a useful basis for defining functional regions. A commuting area is conceived as a geographical area within which there is a high degree 
of interactivity and may be seen as an appropriate spatial region to capture the interplay between labour supply and demand. Mitchell et al. [17] concluded that aggregations of journey-to-work data reflect economic behaviour rather than administrative structures.

The objective of this paper is to analyse journey-to-work flow data and to use intramax analysis to establish functional regions in South Africa in general, but specifically at provincial level. The purpose is to demonstrate how functional regions differ from administrative regions (which are more than likely demarcated in terms of political or ideological philosophy). A further objective is to test whether the functional regions or provinces identified by the intramax analysis are economically viable regions.

\section{Literature review on analysis of flow data}

Journey-to-work data may be captured in a network flow problem, which consists of a collection of transhipment nodes connected by directed arcs in both directions. Figure 2 contains an example of journey-to-work data between four regions.

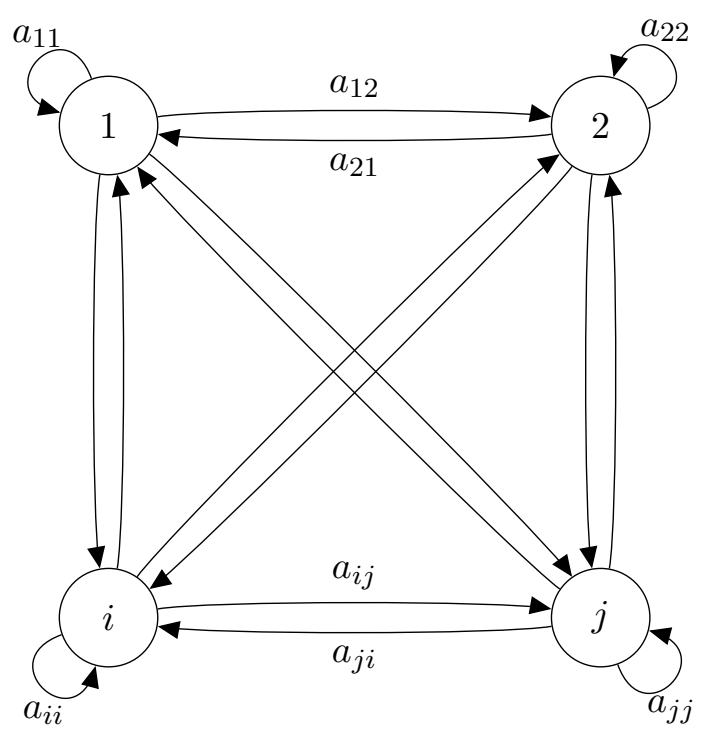

Figure 2: Example of a network of flows between 4 regions.

A schematic representation of a so-called interaction matrix is provided in Table 1, where rows are designated as origins and columns are destinations. Marginal totals may be interpreted as follows: $O_{i}=\sum_{j} a_{i j}$ and $D_{j}=\sum_{i} a_{i j}$ represent the total outflow from region $i$ and total inflow into region $j$ respectively.

Ward [26] developed a hierarchical aggregation procedure which is a routine for searching through groups of data to find which pair of basic data units shows the greatest mutual similarity with respect to specified characteristics. Given $k$ subsets, this method permits their reduction to $k-1$ mutually exclusive subsets by considering the union of all possible $\left(\begin{array}{l}k \\ 2\end{array}\right)=k(k-1) / 2$ pairs that can be formed and accepting the union with which an optimal value of the objective function is associated. The process may be repeated until all subsets 


\begin{tabular}{ccccccc}
\hline & Region 1 & Region 2 & $\ldots$ & Region $j$ & $\ldots$ & Total \\
\hline Region 1 & $a_{11}$ & $a_{12}$ & $\ldots$ & $a_{1 j}$ & $\ldots$ & $\sum_{j} a_{1 j}=O_{1}$ \\
Region 2 & $a_{21}$ & $a_{22}$ & $\ldots$ & $a_{2 j}$ & $\ldots$ & $\sum_{j} a_{2 j}=O_{2}$ \\
$\vdots$ & $\vdots$ & $\vdots$ & $\ddots$ & $\vdots$ & $\ddots$ & $\vdots$ \\
Region $i$ & $a_{i 1}$ & $a_{i 2}$ & $\ldots$ & $a_{i j}$ & $\ldots$ & $\sum_{j} a_{i j}=O_{i}$ \\
$\vdots$ & $\vdots$ & $\vdots$ & $\ddots$ & $\vdots$ & $\ddots$ & $\vdots$ \\
Total & $\sum_{i} a_{i 1}=D_{1}$ & $\sum_{i} a_{i 2}=D_{2}$ & $\ldots$ & $\sum_{i} a_{i j}=D_{j}$ & $\ldots$ & $\sum_{i} \sum_{j} a_{i j}=n$ \\
\hline
\end{tabular}

Table 1: Journey-to-work interaction matrix.

are in one group.

Ward [26] defines a functional relation that provides a "value reflecting" number as an objective function. It is common practice to use the mean value to represent all scores. The loss in information that results from treating scores as one group may be indicated by a "value-reflecting" number such as the Error Sum of Squares (ESS). The ESS is given by

$$
E S S=\sum_{i=1}^{m}\left(x_{i}-\bar{x}\right)^{2}=\sum_{i=1}^{m} x_{i}^{2}-\frac{1}{m}\left(\sum_{i=1}^{m} x_{i}\right)^{2},
$$

where $x_{i}$ is the score of the $i$-th individual and where $m$ denotes the number of individuals. If scores are classified in groups, the grouping can be evaluated as the sum of the ESS values, that is

$$
E S S_{\text {Groups }}=E S S_{(\text {Group 1) }}+E S S_{(\text {Group 2) }}+\ldots
$$

The same procedure can be used for aggregation of flow data if the objective function is respecified in terms of the two-directional flow between two regions. It will be necessary to consider two entries for this purpose, namely $a_{i j}$ and $a_{j i}$, for all $i \neq j$.

Masser and Brown [14] formulated as objective the maximisation, at each stage of the grouping process, of the difference between the observed values, $a_{i j}$, and "expected values" $a_{i j}^{*}$, which are derived similarly to the expected frequency of the cell in row $i$ and column $j$ in a contingency table for the Chi-square test, namely

$$
a_{i j}^{*}=\frac{O_{i} D_{j}}{n}, \quad \text { where } n=\sum_{i} \sum_{j} a_{i j} .
$$

The objective is therefore to

$$
\underset{i \neq j}{\operatorname{maximise}}\left\{\left(a_{i j}-a_{i j}^{*}\right)+\left(a_{j i}-a_{j i}^{*}\right)\right\} .
$$

The entries $a_{i j}$ are standardised so that

$$
\sum_{i} \sum_{j} a_{i j}^{\prime}=1
$$


where $a_{i j}^{\prime}=a_{i j} / n$. It can be shown that the standardised objective is to

$$
\underset{i \neq j}{\operatorname{maximise}}\left\{\left(a_{i j}^{\prime}-a_{i j}^{*}\right)+\left(a_{j i}^{\prime}-a_{j i}^{*}\right)\right\} .
$$

Contiguity constraints may be introduced to restrict the search for potential pairings. These constraints may take the form $c_{i j}=1$, if movement of a basic data unit from $i$ to $j$ is allowed, and $c_{i j}=0$ otherwise.

The intramax analysis is a stepwise analysis. During each step two areas are grouped together and the interaction between the two areas becomes internal (or intrazonal) interaction for the new resulting area. This new area now takes the place of the two parent areas at the next step of the analysis. So with $N$ areas, all areas are grouped together into one area after $N-1$ steps and all interaction is intrazonal. The outcome of an intramax analysis may be presented in dendrogram form.

According to Tyree [24], the alternative concept of mobility ratios was developed by three sociologists, Natalie Rogoff, David Glass and Gösta Carlsson [24], working independently on the problem of intergenerational occupational mobility. A matrix of frequencies of occupations of respondents by occupations of fathers may be converted into matrices of inflow and outflow percentages. The mobility ratio $M_{i j}$ is simply the ratio

$$
M_{i j}=\frac{a_{i j} n}{O_{i} D_{j}}, \quad i \neq j,
$$

of the frequency observed in a cell to the frequency expected under the assumption of statistical independence. Hollingworth [13] studied migration between Scottish executive areas and also defined the mobility index as (1). The value of the objective function in this case is then $M_{i j}+M_{j i}$, which was used as a symmetric measure of the mutual association of areas $i$ and $j$.

Hirst [12] noted that both the objective functions defined by Masser and Brown [14] and Hollingworth [13] is inappropriate, because of the influence of unequal marginal distributions which define the expected frequencies. For example, the ratio or difference between the observed and expected values will tend to increase for cells in those rows and columns with large sums. Since the objective function is recalculated after each step in the grouping procedure, this bias will be cumulative.

Tyree [24] suggested that the interaction matrix should first be adjusted to achieve an arbitrary origin-destination distribution. This may be accomplished iteratively by standard matrix operations: rows are scaled initially to sum to a given total, and then columns are scaled to sum to the same total. This procedure is repeated until sufficient convergence occurs to a matrix in which all row and column sums are simultaneously equal. Hirst [12] claimed that it can be proved that this matrix exists, is unique, and that the iterative procedure is convergent. He suggested that a possible solution would be to divide $a_{i j}^{\prime}-a_{i j}^{\prime *}$ by $a_{i j}^{\prime *}$, with $a_{i j}^{\prime *}$ corrected for blank entries in the interaction matrix as proposed by Goodman [7], but noted that results will still tend to favour small zones, because of the differences between the values obtained for small as opposed to large zones. Hirst also remarked that an increasing number of heuristic techniques has become available, and that a need for comparative evaluation of their respective merits and areas of application has arisen. 
Masser and Scheurwater [15] evaluated three methods for functional regionalisation, namely the functional distance method [1] (not discussed in this paper), the iterative proportional fitting based procedure (IPFP) [20] (not discussed in this paper) and the intramax procedure [14]. Their conclusion was that the intramax procedure is the only one of the three procedures which explicitly identifies regions that have more (direct) interaction with each other than with other areas at each stage of the grouping process. It has a practical advantage over the other two methods, because it only involves a series of direct comparisons between the observed and expected values that are calculated by the multiplication of the respective row and column totals. This avoids the complex set of matrix manipulations that are required for the other two methods. The intramax procedure may be more readily applied to large data sets and may be adapted more easily to deal with large, sparse matrices. Masser and Scheurwater [15] also noted that stronger connections would appear between pairs of smaller zones containing a relatively low proportion of intrazonal interaction than between pairs of larger zones containing a relatively high proportion of intrazonal interaction and that the former would tend to fuse together before the latter. They reason that this bias noted by Hirst [12], far from being a disadvantage, is in fact advantageous and that it is a reflection of the inherent characteristics of the structure of spatial interaction in the matrix.

Fischer et al. [5] compared the intramax procedure with the IPFP-based graph approach (not discussed in this paper) and came to the conclusion that the intramax approach is superior to the IPFP-based graph-theoretical one, because the results are easily interpretable in terms of functional regions. The intramax approach also leads to spatial groupings which show more interaction with each other than with other regions.

Brown and Pitfield [2] noted that the objective function was reformulated in literature appearing after the comment of Hirst [12] to

$$
\underset{i \neq j}{\operatorname{maximise}}\left\{\frac{a_{i j}^{\prime}-a_{i j}^{*}}{a_{i j}^{\prime *}}+\frac{a_{j i}^{\prime}-a_{j i}^{\prime *}}{a_{j i}^{\prime *}}\right\} .
$$

They remarked that this revised form of the objective function was employed in all subsequent applications of the procedure, and may be re-expressed a little more simply as

$$
\underset{i \neq j}{\operatorname{maximise}}\left\{\frac{a_{i j}^{\prime}}{a_{i j}^{\prime *}}+\frac{a_{j i}^{\prime}}{a_{j i}^{\prime *}}\right\} .
$$

The reason for this is that the part that is subtracted in each term is constant and may thus be ignored. This objective function is also discussed by Brown and Pitfield [2]. The resulting formula is strikingly similar to the mobility ratios employed by Hollingworth [13], where

$$
\frac{a_{i j}^{\prime}}{a_{i j}^{\prime *}}=\frac{\frac{1}{n} a_{i j}}{\frac{1}{n} \sum_{j} a_{i j} \frac{1}{n} \sum_{i} a_{i j}}=\frac{n a_{i j}}{\sum_{j} a_{i j} \sum_{i} a_{i j}} .
$$

\section{The software suite Flowmap}

Flowmap [25] is a software suite developed at the University of Utrecht, the Netherlands (in conjunction with the CSIR, South Africa). The suite performs geographical analyses 
and specialises in displaying interaction data (such as commuting and migration flows), interaction analysis (such as accessibility analysis), network analysis, and interaction modelling. The program uses several kinds of data, which may be grouped into three classes: maps, flow data and distance tables.

Flowmap uses intramax analysis to identify functional regions from an interaction matrix.

"The objective of the intramax procedure is to maximise the proportion within the group interaction at each stage of the grouping process, while taking account of the variations in the row and column totals of the matrix" [22]. This implies that in this particular case two areas are grouped together for which the objective function

$$
\frac{T_{i j}}{O_{i} D_{j}}+\frac{T_{j i}}{O_{j} D_{i}}
$$

is maximised where $T_{i j}$ is the interaction between origin location $i$ and destination location $j$, and where

$$
O_{i}=\sum_{j} T_{i j} \text { and } D_{j}=\sum_{i} T_{i j}
$$

This is similar to (2) and the method of Hollingsworth [11], but the constant $n$ is omitted. The objective function in (3) can only be calculated for all $D_{j}>0$ and for all $O_{i}>0$. In Flowmap actual flow values are used, hence $T_{i j}$ instead of $a_{i j}^{\prime}$, but that should not have any effect on the results as no comparisons are made; the maximum relationship is merely sought at each aggregation step. The use of the above objective function is also substantiated in a thesis by Floor and de Jong [6].

\section{Methodology and data}

The methodology employed and the data used in this paper are described in this section.

\subsection{Journey-to-work data and intramax analysis}

The data used in this paper all derive from the 2001 South African Census [22]. The question was asked "In the seven days before 10 October did (the person) do any work for pay (in cash or in kind), profit or family gain, for one hour or more? If "Yes," does (the person) work in the same sub-place in which s/he usually lives?" If "No," the main place of work was recorded. The definition of work includes formal, informal and seasonal work. The database of all persons between the age of 15 to 65 represented 28427129 individuals. A subdatabase was prepared at the request of the authors containing amongst others, the following fields: main place code and main place of work code. For reasons of confidentiality, records were totalled and frequencies in each category, defined by the field names, were calculated. The resulting subdatabase contained a total of 1890827 records. Part of the confidentialising process was to change frequencies of 1 and 2 according to an algorithm, as follows:

- Change a frequency of 1 to 0 in two thirds of the cases;

- Change a frequency of 1 to 3 in one third of the cases; 
- Change a frequency of 2 to 0 in one third of the cases and

- Change a frequency of 2 to 3 in two thirds of the cases.

Certain records were not considered for the intramax analysis ${ }^{1}$. The records not considered included 198758 records (18792972 individuals) for which the main place of work were marked as not applicable, due to the fact that these records represent persons unemployed or not economically active. A further 65556 records (156899 individuals) were deleted, because the main place of work was "unspecified." Of the remaining records, a further 107818 records (182 237 individuals) were removed due to the fact that they replied "No" to the question "Is this your usual place of stay?" A further 3997 records (9679 individuals) were deleted because their economic activity was marked "Not economically active." Some further 32290 records (59 933 individuals) were deleted because the main place names could not be matched (the province code was given instead of the code of a specific main place).

The following data cleanup was also performed and the interaction data were adjusted accordingly:

- 7 islands were removed,

- 638 fully embedded regions were dissolved,

- 24 main places without interaction were dissolved,

- 46 main places with only intrazonal interaction were dissolved.

Intramax analysis was therefore applied to a total of 861939 records involving 2393 extended main places.

\subsection{Principal component and cluster analysis}

It is important to validate the results, e.g. to use different methods with different variables to establish whether boundaries and regions defined by the intramax analysis may be viewed as socio-economic functional regions. Harmse [10], using mainly 1996 Census data, demarcated the South African space economy into a hierarchy of five development regions, i.e. a highly developed metropolitan core region, an upward transitional region, a downward transitional region, a resource frontier region and special problem regions. Harmse et al. [11] reapplied this technique on 2001 Census data, using the following socioeconomic variables:

- Population density,

- Birth rate,

- Youthful dependency ratio,

- Per capita income,

- Number of persons per 10000 earning more than R51 201 per month,

- Percentage of people employed,

- Number of people per 1000 working in agriculture,

- Number of people per 1000 working in secondary sector,

- Number of people per 1000 working in financial services,

\footnotetext{
${ }^{1}$ Only employed persons for whom journey-to-work data per main place could be calculated are included.
} 
- Percentage of people living in urban areas,

- Number of people per 1000 with more than 12 years of education,

- Percentage of households whose refuse is removed by local authority,

- Percentage of households living in formal housing,

- Percentage of households using electricity for cooking, and

- Percentage of households with piped water in the house.

A data matrix consisting of variables and municipalities as spatial units was compiled as input for the multivariate analysis. Using principal component analysis, the large number of correlated variables was reduced to fewer variables that captured most of the variation in the original variables. Cluster analysis was then used to identify groups of similar main places in order to reduce the number of spatial units to a more manageable number, using the scores of the different principal components. By applying Ward's cluster analysis, the semi-partial $R^{2}$ values generated was used to identify a significant grouping. The mean score on principal component I for these different groups was calculated in order to determine how the groups may be assigned to the different regional types [10]. The results are reported in the following section.

The Community Profile database [23] of Census 2001 was accessed in SuperCross format at main place level. The weighted mean, median and inter quartile range of some socio-economic variables were calculated for a proposed five-province scenario and were compared using Bonferroni multiple comparisons.

\section{Results}

\subsection{Intramax analysis}

A total of 2392 iterations were required in the intramax process. At each stage of the clustering process, two regions with the strongest possible commuting ties were aggregated. These two regions were then seen as one region, and commuting between these two regions become intrazonal. The total number of regions was thus reduced by one region and the interaction matrix was reduced by one row and one column. This process was repeated until only one region remained (theoretically), in which all commuting is intrazonal.

During this process, there were 18 minor areas exhibiting unusually large flows, which were not clustered - they remained original main places. For example, the Kgalagadi Park (main place 39 302) in the Northern Cape has only outside commuter links and comprises a total of 7 persons all residing/working in the Saldanha area over $800 \mathrm{~km}$ away. The flows to/from the 18 problem main places were removed. Other surviving unlinked main places were also removed or dissolved, yet ensuring that this process did not impact on the boundaries of the remaining clusters.

The clustering process continued until $80 \%$ of the interzonal interaction internalised with 70 functional areas (blocks) remained. The results are shown in the dendrograms in Figures 3-7 and the map in Figure 8.

In Figure 3, the Nama Khoi region includes the town of Springbok and the Richtersveld National Park. This fuses with the Matzikama region, which includes Van Rhynsdorp, 


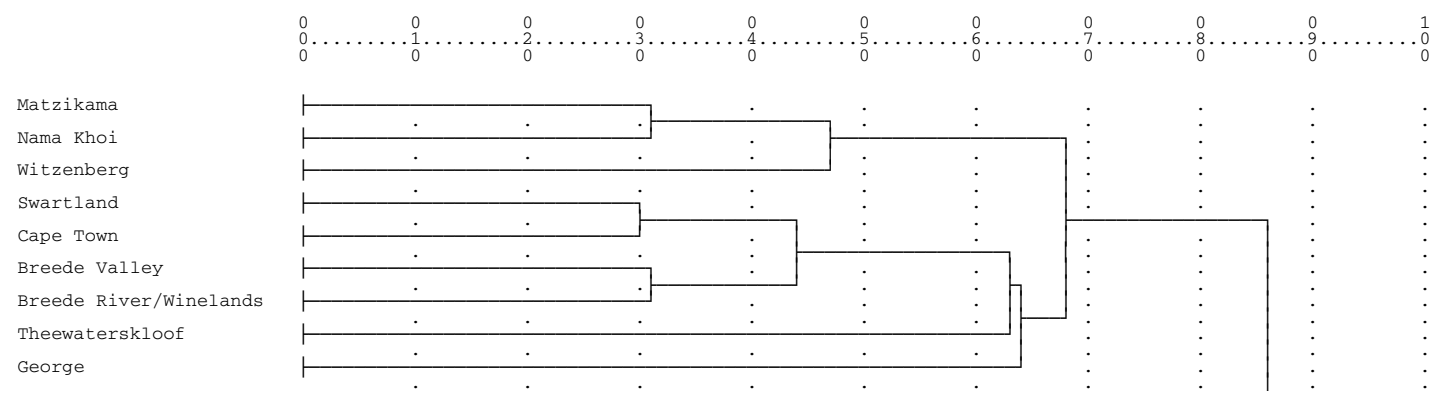

Figure 3: Dendrogram of the last nine regions in the Western Cape.

Vredendal, Calvinia, Sutherland, Carnarvon and others. Approximately $31 \%$ of all the journey-to-work flows in and out of these regions are intrazonal for this new aggregation. In the next step, this region fuses with the Witzenberg region, which includes places such as Ceres, Tulbach and Clanwilliam (47\% intrazonal). The Cape Town region (including Stellenbosch, Strand, Paarl, etc.) fuses with the Swartland region, which includes Moorreesburg, Malmesbury, Saldanha and others (30\% intrazonal). The Breede River/Winelands area (Montagu, Swellendam, etc.) fuses with the Breede Valley area (Worcester, Robertson, etc.) (31\% intrazonal), which then fuses with the Cape Town / Swartland cluster (44\% intrazonal). This cluster then fuses with the Theewaterskloof cluster (63\% intrazonal), which includes the Overberg region. The George cluster (which includes most of the Garden Route) fuses with the larger Cape Town cluster (64\% intrazonal), and finally this fuses with the Witzenberg / Nama Khoi / Matzikama cluster (68\% intrazonal). ('First Province' of the nine last clusters shown in Figure 8.)

In Figure 4, the Paradise Beach and Kouga areas (Jeffreys Bay, Tsitsikamma National park, Stormsriver area) merges with the Port Elizabeth area (30\% intrazonal), and fuses in the next step with the Ubuntu area (including Victoria West, Richmond, etc.) and the Inxuba Yethemba region (Cradock, Middelburg, etc.) (31\% intrazonal). This region then fuses with the Graaff Reinet area (47\% intrazonal). The Grahamstown and East London regions (31\% intrazonal) fuse with the Lusikisiki (including Flagstaff), Queenstown, Kokstad and Marburg (Port Shepstone and others) regions (63\% intrazonal). This region then fuses with the greater Port Elizabeth cluster ( $67 \%$ intrazonal). ('Second Province' of the nine last clusters shown in Figure 8.)

In the second part of Figure 4, the Durban and Pietermaritzburg regions (34\% intrazonal) merge with the Umvoti (Greytown, Kranskop, etc.) and Stanger regions (43\% intrazonal). The Myeni/Ntsinde area (Jozini, etc.) fuses with the Richards Bay area (31\% intrazonal), and this region fuses next into the greater Durban region, followed by the Mkhambathini region, which looks like a region on its own (Camperdown, etc.) (69\% intrazonal). ('Third Province' of the nine last clusters shown in Figure 8.)

The third part of Figure 4 consists of the Ladysmith region (including Escourt, etc.) and the Newcastle region (including the Volksrust and Standerton areas in the current Mpumalanga Province) (45\% intrazonal). ('Fourth Province' of the nine last clusters shown in Figure 8.) 

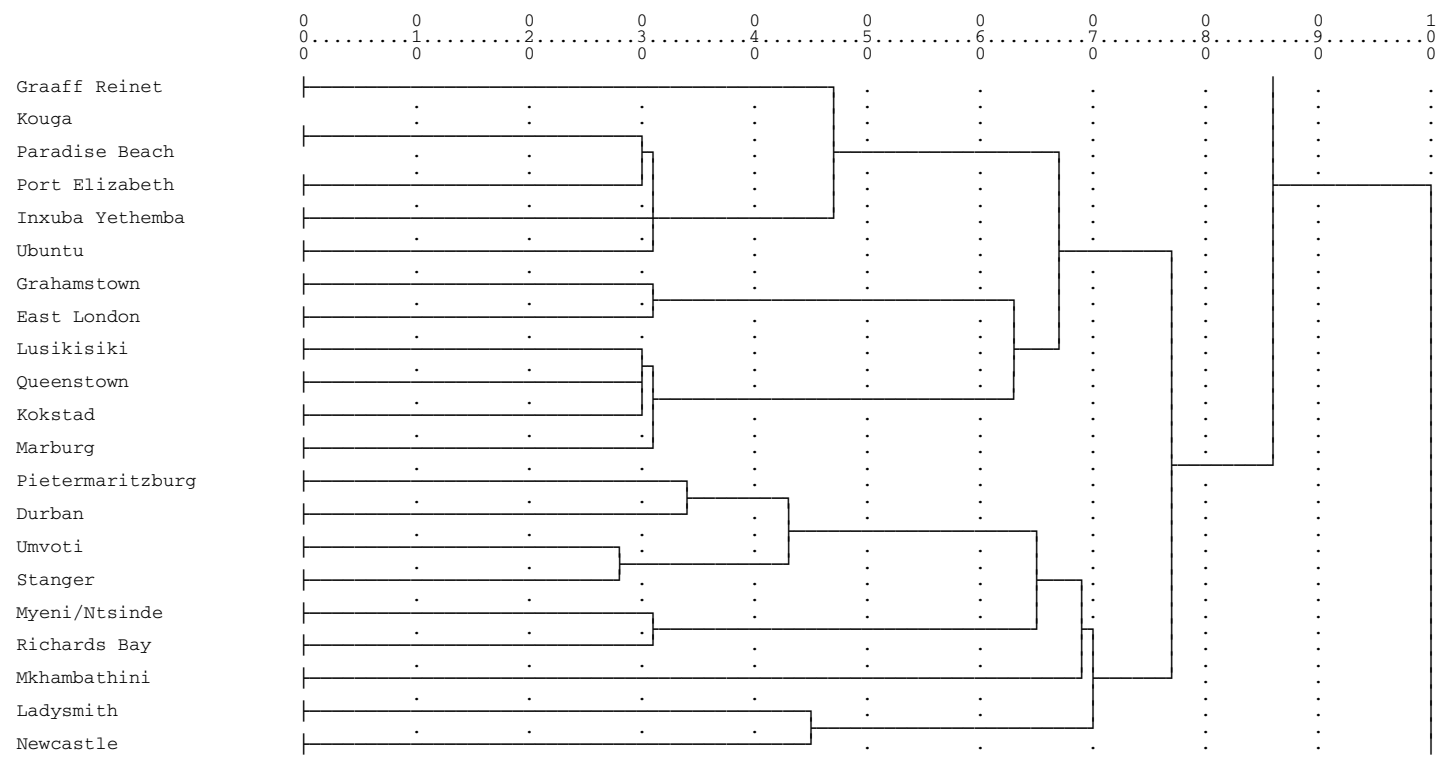

Figure 4: Dendrogram of the last twenty-one regions in the Eastern Coastal region. Kouga and Paradise Beach merge at the very start of the procedure resulting in less than $0.5 \%$ intrazonal interaction.

In Figure 5 the Dukathole (including Jamestown in the current Eastern Cape and Aliwal North) and Kopanong (Bethulie, Philippolis, etc.) areas fuse (31\% intrazonal). This region then fuses with the Naledi (Van Stadensrus, Wepener, etc.) and Bloemfontein regions and the resulting region results in $47 \%$ intrazonal flows. The Setsoto (Clocolan, Ficksburg, Senekal), Nketoana (Lindley, Reitz, Petrus Steyn), Phuthaditjhaba and Phumelela (Memel, Vrede and Warden) regions merge (47\% intrazonal flow) and this region fuses with the greater Bloemfontein region (68\% intrazonal). The Tswelopele (Bultfontein and Hoopstad), Maquassi Hills (Leeudoringstad and Makwassie regions in the current North West Province), Thabong (Odendaalsrus and Welkom), Nala (Bothaville regions), Moqhaka (Kroonstad and Steynsrus) and Klerksdorp region in the current North West Province fuse ( $48 \%$ intrazonal) which then fuse with the previous region, including Bloemfontein, (69\% intrazonal) to form the 'Fifth Province' of the nine last clusters shown in Figure 8.

In Figure 6, the regions of Kai !Garib (Augrabies, Kakamas and other regions in the Northern Cape) and !Kheis (Groblershoop, Grootdrink, etc. in the Northern Cape) merge with the Kimberley, Letsemeng (Petrusburg, Jacobsdal, etc. in the Free State) and Vryburg (also Schweizer-Reneke and other regions in the North West Province) regions (47\% intrazonal). This region merges with the Rustenburg and Mafikeng fusion (69\% intrazonal), resulting in the 'Sixth Province' of the nine last clusters shown in Figure 8.

The Modderfontein region merges with the Boksburg, Johannesburg fusion (28\% intrazonal), and the Evaton (Vaal Triangle, including Sasolburg in the Free State) and Lesedi (Heidelberg, Nigel Springs) regions then fuse into the Johannesburg region (46\% intrazonal), then follow the Pretoria region, the Randfontein region and lastly the Merafong (Carltonville, Khutsong and others) region (66\% intrazonal). This results in the 'Seventh 


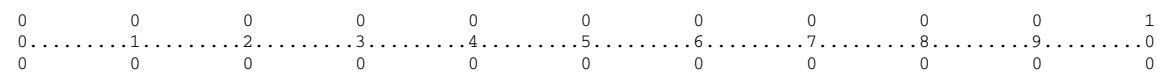

Dukathole

Kopanong

Naledi

Bloemfontein

Setsoto

Nketoana

Phuthaditjhaba

Phumelela

Tswelopele

Maquassi Hills

Thabong

Nala

Moqhaka

Klerksdorp

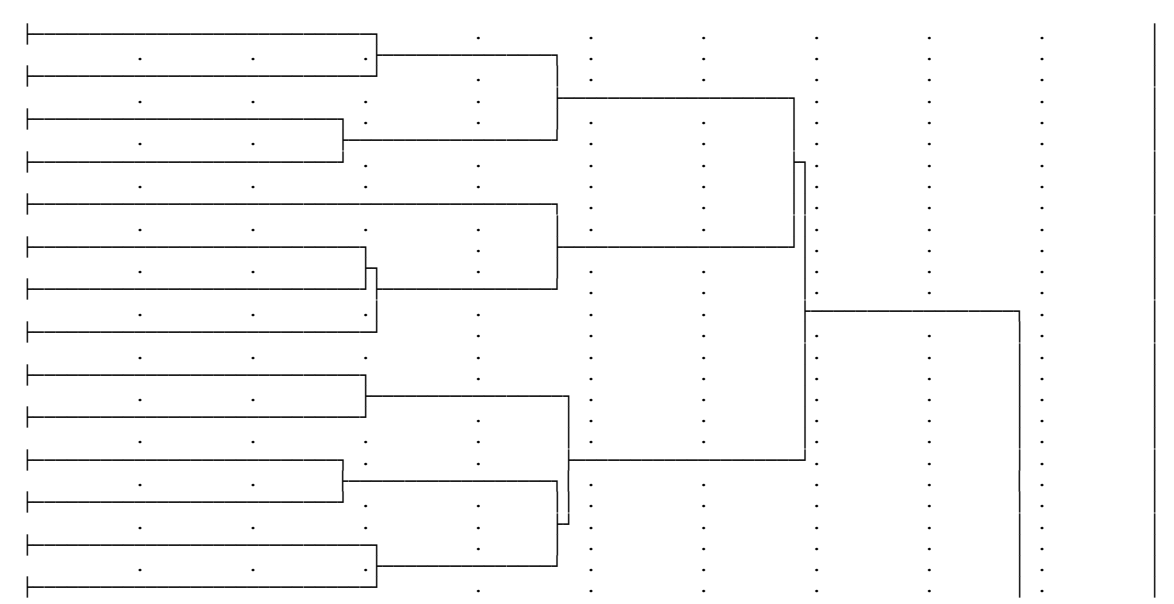

Figure 5: Dendrogram of the last fourteen regions in the Central region.

Province' of the nine last clusters shown in Figure 8.
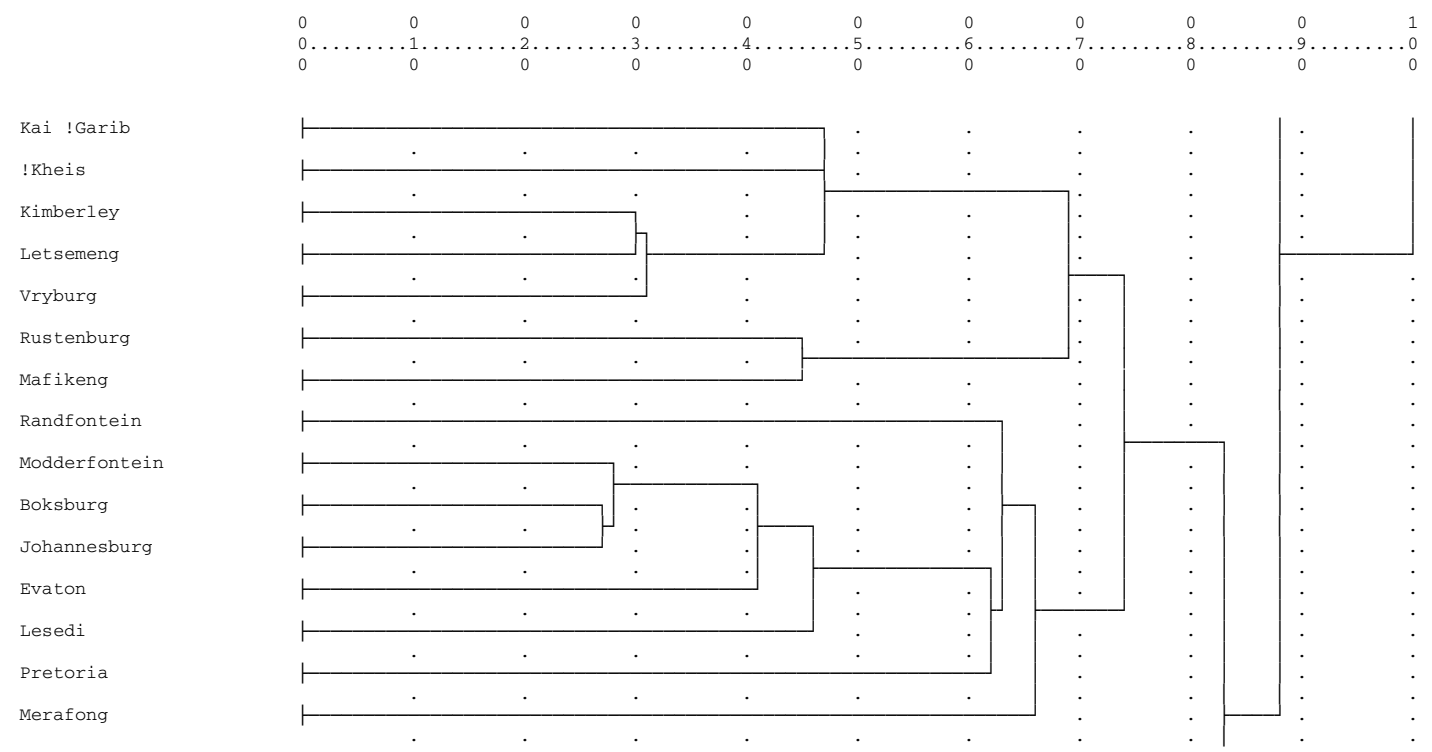

Figure 6: Dendrogram of the last fifteen regions in the Gauteng region.

Figure 7 is a fusion of the remaining regions of the Limpopo Province and the Mpumalanga Province. Msukaligwa (Ermelo region) and Mkhondo (Piet Retief region) merge with Embalenhle (Kinross, Leslie, Evander regions) and Witbank region (48\% intrazonal). The Highlands (Dullstroom, Machadodorp regions) and Mbombela (Nelspruit region) regions merge with the greater Witbank region (67\% intrazonal) which completes the 'Eighth Province' of the nine last clusters shown in Figure 8. 
Finally the Greater Tzaneen (including Haenertsburg, Letsitele, etc.) and Phalaborwa (including Gravelotte, Die Eiland, etc.) regions merge (28\% intrazonal). The Pietersburg region (Polokwane) fuses with the Tzaneen region (45\% intrazonal), followed by a fusion with the Tshivhase region (Thohoyandou, Gijana, etc.) and lastly the Bela-Bela region (Warmbaths, Nylstroom, etc.), with a total of $67 \%$ intrazonal flow, resulting in the 'Ninth Province' in Figure 8.
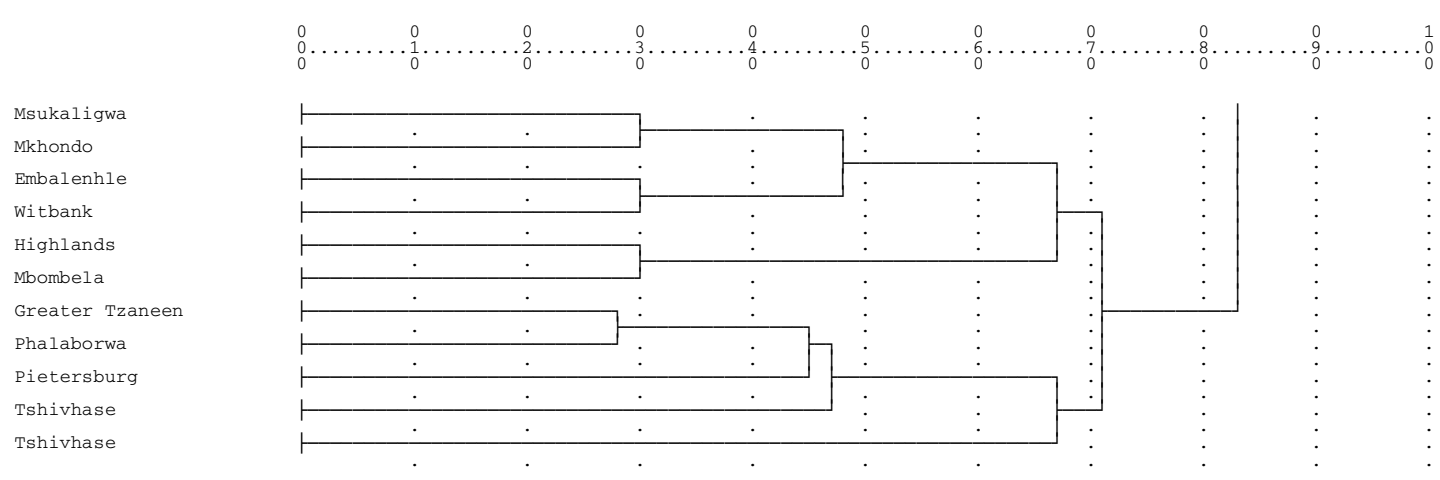

Figure 7: Dendrogram of the last eleven regions in the Northern region.

The dots in Figure 8 are proportional to the volume or level of intrazonal interaction per new functional block and the nine-province division shown in the figure has been constructed by means of the intramax method from the interaction between the remaining 70 blocks.

Tables 2 and 3 show the commuter flows crossing provincial boundaries in the current context and the proposed new situation with nine provinces. The number of boundarycrossing commuters is reduced in the intramax solution by over $45 \%$ from 287000 to approximately 157000 . The total workforce is approximately 9.4 million, but only some 2.7 million workers commute daily between different main places. The difference between the total workforce and the part of the workforce that actually commutes explains the difference between the numbers in Tables 2 and 3 and the numbers given in $\S 5.1$.

\subsection{Reducing the number of provinces to four or five}

The dendrograms in Figures 3 to 7 show that 'Province 4' (Newcastle region) fuses with 'Province 3' (Durban region) (69\% intrazonal). Next, the remainder of the Mpumalanga region ('Province 8') fuses with the remainder of the Limpopo Province ('Province 9') (71\% intrazonal). Next follows the remainder of the North West region ('Province 6'), which fuses with the greater Gauteng area ('Province 7') (73\% intrazonal). The Eastern Cape region ('Province 2') clusters together with the KwaZulu-Natal region ('Province 3') (77\% intrazonal) leaving a remainder of five 'provinces', i.e. the Western Cape with part of the Northern Cape; an amalgamation of the Eastern Cape and KwaZulu-Natal; an amalgamation of the North West and Free State; an amalgamation of the remainder of the Northern Cape, North West and Gauteng; and an amalgamation of Limpopo Province and the remainder of Mpumalanga (five provinces). In the next step, the newly formed Limpopo Province would fuse with the Gauteng region (four possible provinces), 


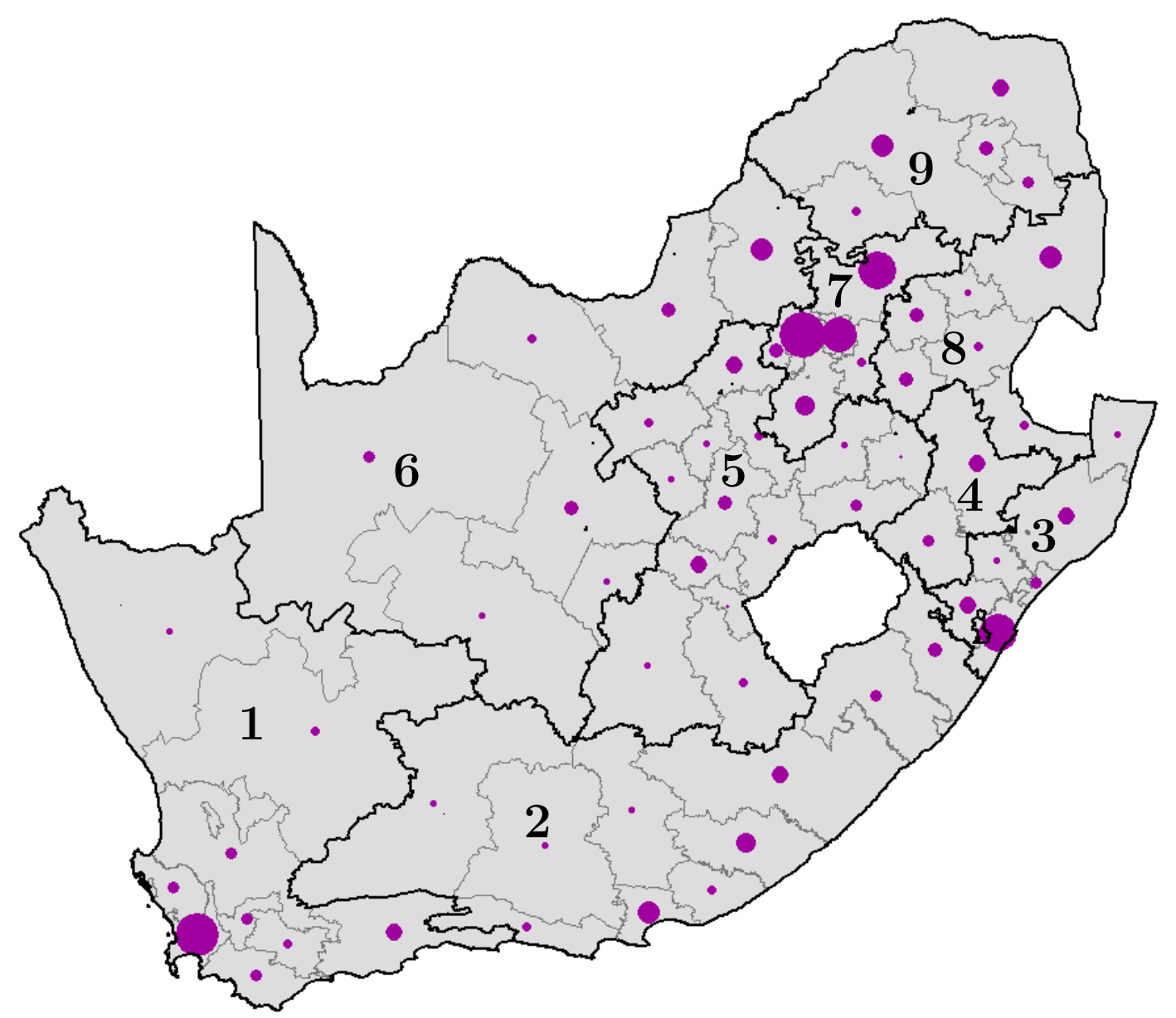

Figure 8: The remaining nine clusters with dots indicating the relative size of the intrazonal interaction per functional region.

the Eastern Cape and KwaZulu-Natal region would fuse with the Western Cape region (three provinces) and the Free State region would amalgamate with the Gauteng region (two provinces). The country thus becomes consolidated into a final North-South division.

The boundaries between the Western Cape region and the Eastern Cape / KwaZulu-Natal region are mountainous regions, but it seems that rivers, such as the Orange River and the Vaal River, which were historical boundaries, do not impact as much on the boundaries any longer, because of the accessibility via roads to the nearest major centres.

Figure 9 shows the reduction from nine provinces to four provinces.

\subsection{Disputed areas}

The disputed area of Bushbuckridge is used as an example to demonstrate how the intramax analysis may be used to resolve similar contentious situations. The current provincial boundary crosses straight through the Buschbuckridge functional area and generates five times more cross-boundary commuting than the alternative suggested by intramax. 


\begin{tabular}{lrrrrrrrrrr}
\hline $\begin{array}{l}\text { Pro- } \\
\text { vince }\end{array}$ & $\begin{array}{r}\text { Total } \\
\text { flow }\end{array}$ & EC & FS & GP & KZN & LP & MP & NW & NC & WC \\
\hline EC & 163998 & 149004 & 1064 & 2870 & 4556 & 665 & 966 & 1279 & 368 & 3226 \\
FS & 92398 & 880 & 81951 & 5679 & 772 & 350 & 419 & 1059 & 530 & 758 \\
GP & 1007615 & 5325 & 6781 & 957885 & 6314 & 3483 & 7234 & 14313 & 1351 & 4929 \\
KZ & 415992 & 7593 & 992 & 5826 & 392881 & 1893 & 2306 & 1174 & 590 & 2737 \\
LP & 129898 & 1438 & 545 & 5926 & 1399 & 108316 & 10215 & 1098 & 436 & 525 \\
MP & 132701 & 1023 & 893 & 33515 & 1666 & 2093 & 91377 & 1196 & 415 & 523 \\
NW & 240823 & 1100 & 1640 & 86974 & 755 & 6467 & 872 & 137311 & 5180 & 524 \\
NC & 27245 & 312 & 349 & 607 & 138 & 166 & 574 & 467 & 24065 & 567 \\
WC & 479774 & 3812 & 1478 & 4165 & 5374 & 1024 & 566 & 792 & 2143 & 460420 \\
\hline
\end{tabular}

Table 2: Commuter flow within and between the current nine provinces. The following abbreviations are used: $E C=$ Eastern Cape, FS = Free State, GP = Gauteng, KZN = KwaZulu-Natal, LP $=$ Limpopo, $M P=$ Mpumalanga, $N W=$ North West, $N C=$ Northern Cape and $W C=$ Western Cape. Total flow value within provinces: 2403210 (89.32\%). Total flow value between provinces: $287234(10.68 \%)$.

The map in Figure 10(a) shows "major" commuter flows, many crossing the current provincial boundary. The map in Figure 10(b) shows the intramax analysis results after a cleanup into eleven functional areas just before the Buskbuckridge area fuses with the South Kruger Park. The map in Figure 10(c) shows several larger commuter flows into / out of Bushbuckridge across the current provincial boundary.

The intramax results shown in Figure 10(d) allocate the whole of the Bushbuckridge functional area to the southern province and the proposed boundary follows the boundary of the building block instead of cutting through it. Of the 60420 commuters in the area $3771(6.24 \%)$ currently cross the provincial boundary. This number would be reduced to $679(1.12 \%)$ in the proposed provincial split.

The disputed regions of Groblersdal and Marble Hall (Shown in Figure 1) were allocated to Mpumalanga, but transferred to Limpopo province in December 2005 [8]. The intramax analysis indicates that these regions will actually fuse with the Gauteng region. Sasolburg will also fuse into the Gauteng region, and not with the Free State, where it is currently situated.

Kuruman, Postmasburg and Hartswater (currently in the Northern Cape) will be allocated to the North West region, but the boundaries of the North West region will move further south, and include more regions of the Northern Cape, even regions such as Upington, Prieska and De Aar. This is because of the accessibility to Kimberley, which will also be located in the North West region.

The Namaqualand (currently in the Northern Cape), Clanwilliam and Van Rhynsdorp (currently in the Western Cape) regions will be allocated to the Western Cape, and again, here, the N7 route ensures accessibility to the Cape Metropole.

The Pondoland, East Griqualand (currently in the Eastern Cape) and Umzimkulu (currently in the KwaZulu Natal) regions will fuse initially with the Eastern Cape region, but in a four and five province scenario, the Eastern Cape region will fuse with the KwaZuluNatal region, leaving these disputed areas in the middle of the new province. 


\begin{tabular}{rrrrrrrrrrr}
\hline $\begin{array}{r}\text { Pro- } \\
\text { vince }\end{array}$ & $\begin{array}{r}\text { Total } \\
\text { flow }\end{array}$ & CT & QT & DU & NC & Kl & lB & JO & WB & PB \\
\hline CT & 481244 & 461782 & 3930 & 4583 & 546 & 1395 & 2485 & 4658 & 1086 & 779 \\
QT & 184433 & 2773 & 169864 & 3482 & 454 & 1489 & 1343 & 3264 & 981 & 783 \\
DU & 365583 & 2694 & 7529 & 343668 & 2300 & 848 & 1121 & 4955 & 1701 & 767 \\
NC & 28159 & 97 & 438 & 1440 & 23573 & 147 & 79 & 1151 & 505 & 729 \\
Kl & 118382 & 972 & 1267 & 610 & 181 & 108484 & 2363 & 3749 & 398 & 358 \\
lB & 134115 & 942 & 968 & 360 & 170 & 1591 & 119701 & 9086 & 333 & 964 \\
JO & 1160833 & 5473 & 6436 & 4412 & 1296 & 3996 & 10862 & 1117538 & 6246 & 4574 \\
WB & 98406 & 594 & 1037 & 753 & 537 & 729 & 594 & 4930 & 87510 & 1722 \\
PB & 119194 & 499 & 1343 & 879 & 171 & 603 & 1148 & 11021 & 1974 & 101556 \\
\hline
\end{tabular}

Table 3: Commuter flow within and between the last nine clusters. The following abbreviations are used: $C T=$ Cape Town (combination of Western Cape and Northern Cape), QT = Queenstown (mostly Eastern Cape), DU = Durban (mostly KwaZulu-Natal), NC = Newcastle (combination of KwaZulu-Natal and Mpumalanga), KL = Klerksdorp (combination of Free State and North West), $R B=$ Rustenburg (combination of North West and Northern Cape), JO = Johannesburg (mostly Gauteng, with parts of surrounding provinces included), WB = Witbank (remainder of Mpumalanga) and $P B=$ Pietersburg (remainder of Limpopo Province). Total flow value within provinces: 2533676 (94.18\%). Total flow value between provinces: 156673 (5.82\%).

The Brits and Garankuwa areas (currently in the Northwest Province) will also fuse with the Gauteng region.

Since 2001, numerous administrative problems and service delivery constraints associated with cross boundary municipalities prompted a special Presidential Coordinating Council to recommend the scrapping of this municipal category in 2001 [16]. The process of eliminating cross boundary municipalities was completed in December 2005 with the adoption by the National Assembly of the Constitution's Twelfth Amendment Act and the Crossboundary Municipalities Laws Repeal and Related Matters Act, 2005 [3]. Both pieces of legislation effectively eliminated the reality of cross boundary municipalities and demarcated affected municipalities to one province or another. As a result, amongst others, aBushbuckridge, Khutsong, and Matatiele have been incorporated into the Mpumalanga, North West and Eastern Cape provinces respectively. The last two communities have violently resisted the new provincial locations.

Khutsong is part of Merafong municipality which was not indicated as a disputed area in Figure 1. This municipality was partly in the Northwest Province and partly in the Gauteng Province. It was allocated in 2005 to the Northwest Province. According to Figures 6 and 8 the area merges with the 'Seventh Province', which is mostly part of Gauteng.

Matatiele is part of Pondoland in Figure 1, and according to intramax analysis will be incorporated into the Queenstown area, which will, according to Figures 4 and Figure 8, merge with the 'Second Province', which will mostly be the Eastern Cape. 


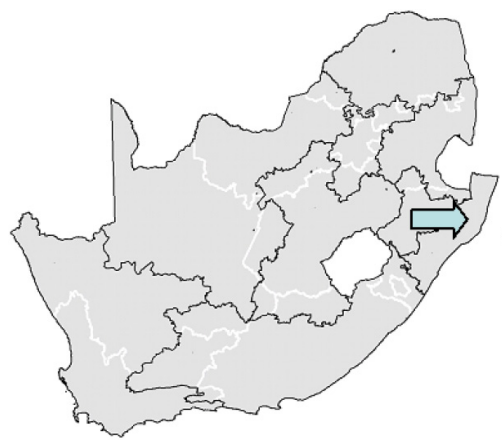

(a) Nine provinces

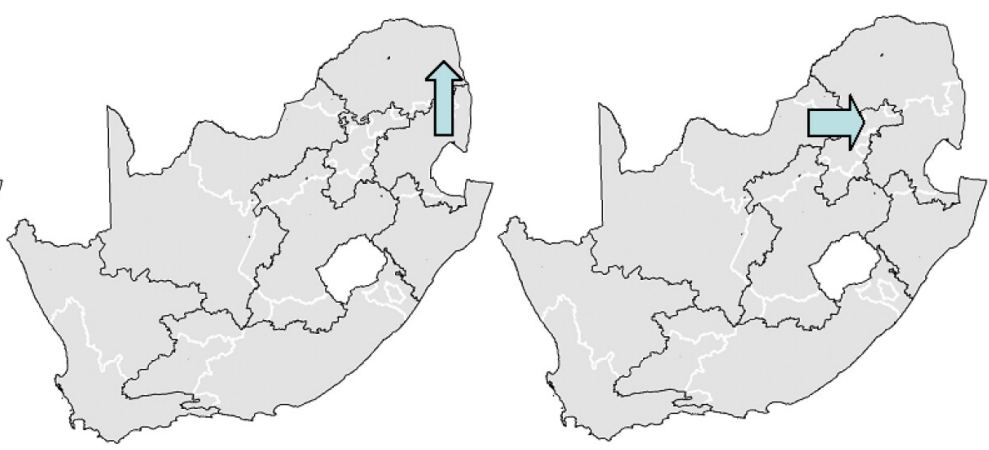

(b) Eight provinces

(c) Seven provinces

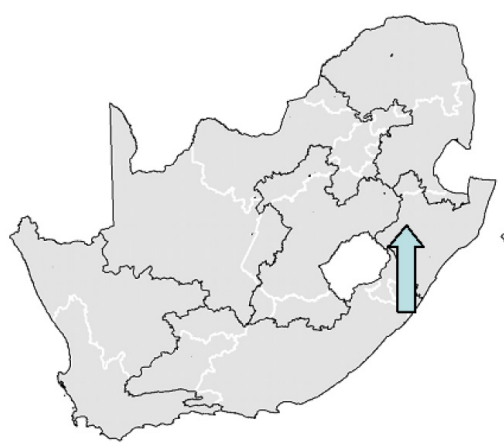

(d) Six provinces

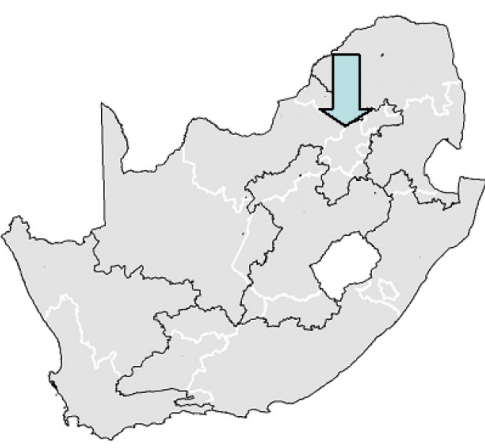

(e) Five provinces

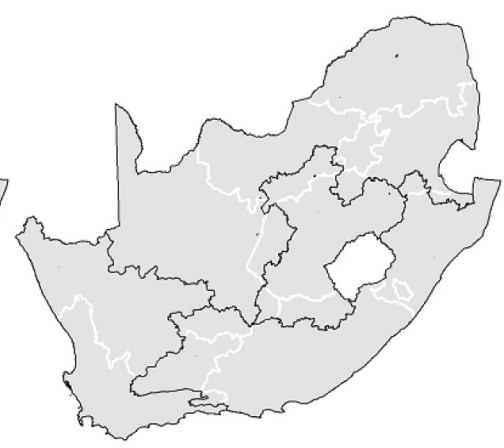

(f) Four provinces

Figure 9: Reduction from nine to four provinces using intramax analysis.

\subsection{Principal component/cluster analysis compared with intramax}

According to Harmse et al. [11] the data matrix, consisting of 16 variables and 249 spatial units, was subjected to a principal component analysis. Three principal components had eigenvalues larger than 1 , and together they were responsible for $77.9 \%$ of the variation in the original data set. The first principal component represented most of the socioeconomic variables, and 10 out of 16 variables had scores of more than 0.75 on principal component I (PC I).

The calculated PC I scores for each of the 249 spatial units comprised a new data set. Cluster analysis was performed on this data set and the most effective grouping of the 249 spatial units resulted in 18 groups, which were then assigned to four regional types. Discriminant analysis was conducted to determine the effectiveness of the groupings.

Figure 11 shows the results of the demarcation of socio-economic development regions in the South African space economy. The 2001 development regions in South Africa ranged from the highly developed core region, through the upward-transitional and downwardtransitional regions, to the special problem regions. According to Harmse et al. [11], the core region has the highest level of development and, in 2001, $69.2 \%$ of the country's total income was earned by people living in the core region. The core region housed $38 \%$ of the country's population on only $5.45 \%$ of the land area. The non-contiguous core region consists of the following regions (in descending order per province): City of Johannesburg 


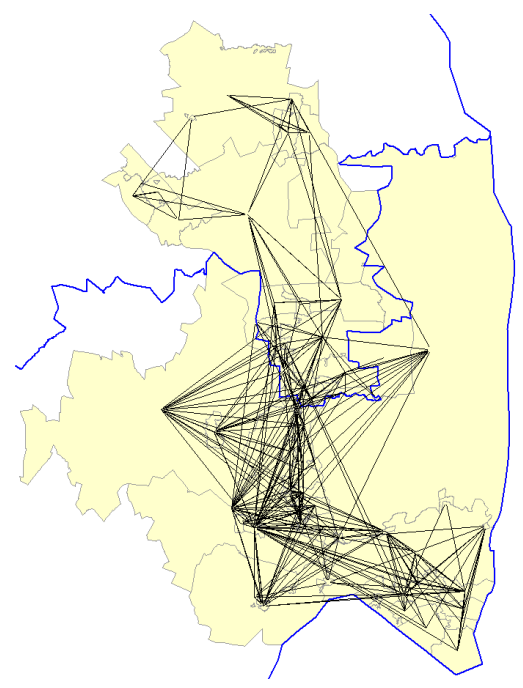

(a) Flows of 10 or more commuters between MPs.

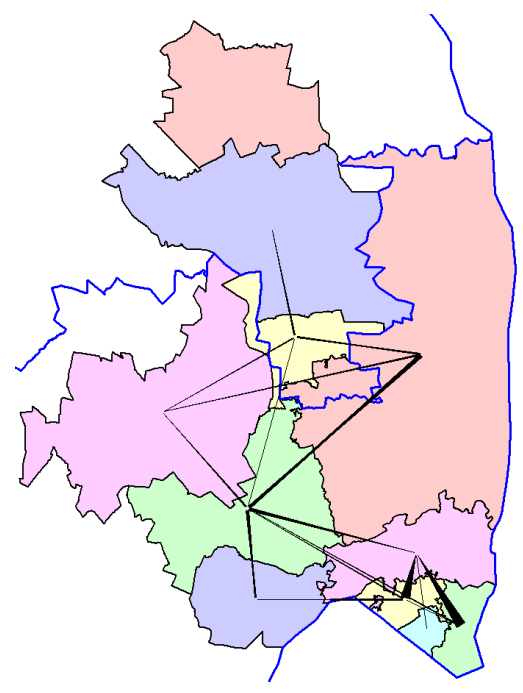

(c) Flows of 100 or more commuters between the functional areas Bushbuckridge has stronger ties to the east (Kruger Park South).

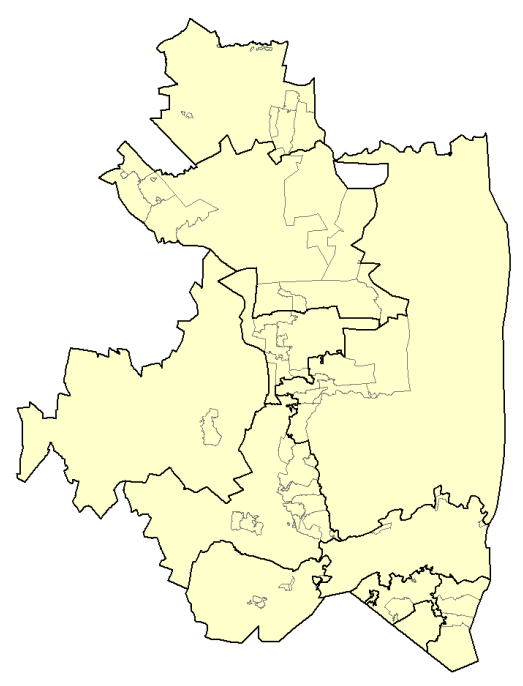

(b) Just before Bushbuckridge merges with a neigbouring area the $74 \mathrm{MPs}$ in the region have clustered to 11 functional areas.

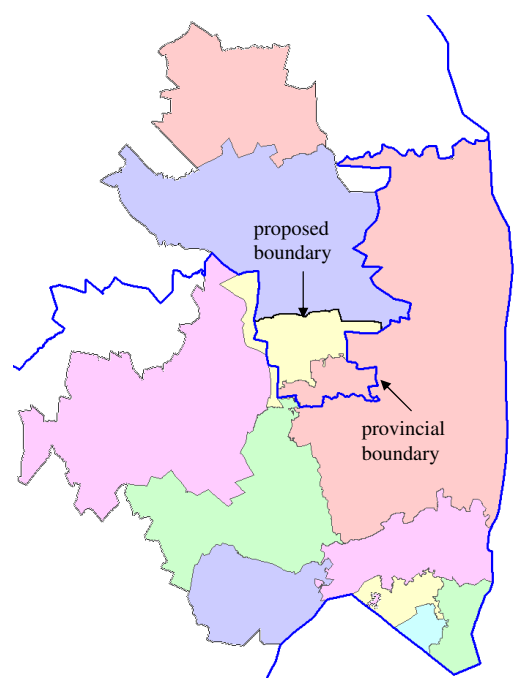

(d) An intramax two way split of the area results in a new provincial boundary.

Figure 10: In-depth analysis of Bushbuckridge as example of a disputed area.

Metro in Gauteng, the Kruger Park in Mpumalanga, City of Tswane Metro in Gauteng, City of Cape Town Metro and Stellenbosch in the Western Cape, Ekurhuleni Metro in Gauteng, Gamagara in the Northern Cape, Midvaal in Gauteng, Mossel Bay in the Western Cape, Ethekwini in KwaZulu-Natal, Mogale City in Gauteng, Overstrand, Cape Agulhas, Saldanha Bay, George and Drakenstein in the Western Cape, Nelson Mandela Metro in the Eastern Cape, uMngeni in KwaZulu-Natal, Kungwini and Randfontein in Gauteng, Potchefstroom in the North West, Emfuleni in Gauteng, Knysna in the Western Cape, 
Nokeng tsa Taemane in Gauteng and the Swartland municipalities in the Western Cape. The Sol Plaatjie municipality in the Northern Cape would be the next on the list.

The levels of the socio-economic development in the 45 districts comprising the upward transitional region were not as high as in the core region, but although the region contains only $13.3 \%$ of the total population, it contributes a further $13.7 \%$ of the total income and $16.7 \%$ of the total number of people employed. These regions are usually adjacent to the core regions.

The 133 districts in the downward transitional region comprise the largest part of the system $(61.1 \%)$. These are usually relatively poorly developed and unintegrated regions. These regions usually make a relatively small contribution towards the economy. In this case, the $33.3 \%$ of the total population only contributes $25.5 \%$ of total employed and $15.0 \%$ of total income.

The 45 districts in the special problem region have the lowest level of development in the space economy. These regions are characterised by very low levels of income and very low levels of employment. In this case, $15.4 \%$ of the population contributes $3.9 \%$ of total employment and $2.1 \%$ of total income. These regions pose a challenge to development [11].

\begin{tabular}{rrrrrr}
\hline & $\begin{array}{r}\text { Special } \\
\text { problem } \\
\text { region }\end{array}$ & $\begin{array}{r}\text { Downward } \\
\text { transitional } \\
\text { region }\end{array}$ & $\begin{array}{r}\text { Upward } \\
\text { transitional } \\
\text { region }\end{array}$ & $\begin{array}{r}\text { Core } \\
\text { region }\end{array}$ & $\begin{array}{r}\text { 13 District } \\
\text { municipalities } \\
\text { excluded }\end{array}$ \\
\hline Number of districts & 45 & 133 & 45 & 26 & 13 \\
\% of total area & 9.9 & 61.1 & 21.2 & 5.5 & 2.4 \\
\% of total population & 15.4 & 33.3 & 13.3 & 38.0 & 0.01 \\
\% of total employed & 3.9 & 25.5 & 16.7 & 53.9 & 0.02 \\
\% of total income & 2.1 & 15.0 & 13.7 & 69.2 & 0.03 \\
\hline
\end{tabular}

Table 4: Contribution of each regional type to selected variables [11].

The last four regions obtained by the intramax analysis were superimposed in Figure 11 on the development regions of the South African space economy, to establish visually some measure of validity of the intramax analysis.

Clearly, the Western Cape region consists of a strong core region and most of the surrounding regions are upward transitional. There are no special problem regions in this province, and one can come to the conclusion that the level of socio-economic development is high, i.e. this province can exist as a unit.

The combination of Gauteng, North West and Limpopo Province also has a strong core region in the Gauteng province, with smaller core regions in the mining areas of the Northern Cape. It has smaller upward transitional areas and larger downward transitional areas with a few problem regions. The strong core should be able to carry these problem regions economically. If this region is sub-divided and the Northern region (Limpopo province) is separated from this region, it might lead to a province (the northern part) with no core region, very little upward transition, large downward transition and problem regions, resulting in the region exhibiting low socio-economic development. This province might be dependent on the government for support. 
In the central province, which is a combination of the Free State and North West provinces, the Potchefstroom region is reflected as a core region, but the Bloemfontein and Kroonstad regions are upward transitional regions. There are no problem regions in this province.

The last region is the combination of the major parts of the Eastern Cape and KwaZuluNatal. Three core areas are identified: the Durban, Pietermaritzburg and Port Elizabeth regions. This region has large problem areas and downward transition regions, compared to upward transition regions. For this region, these three cores can combine their economic power in the combined province, but this province will experience a challenge to survive economically, based on these results.

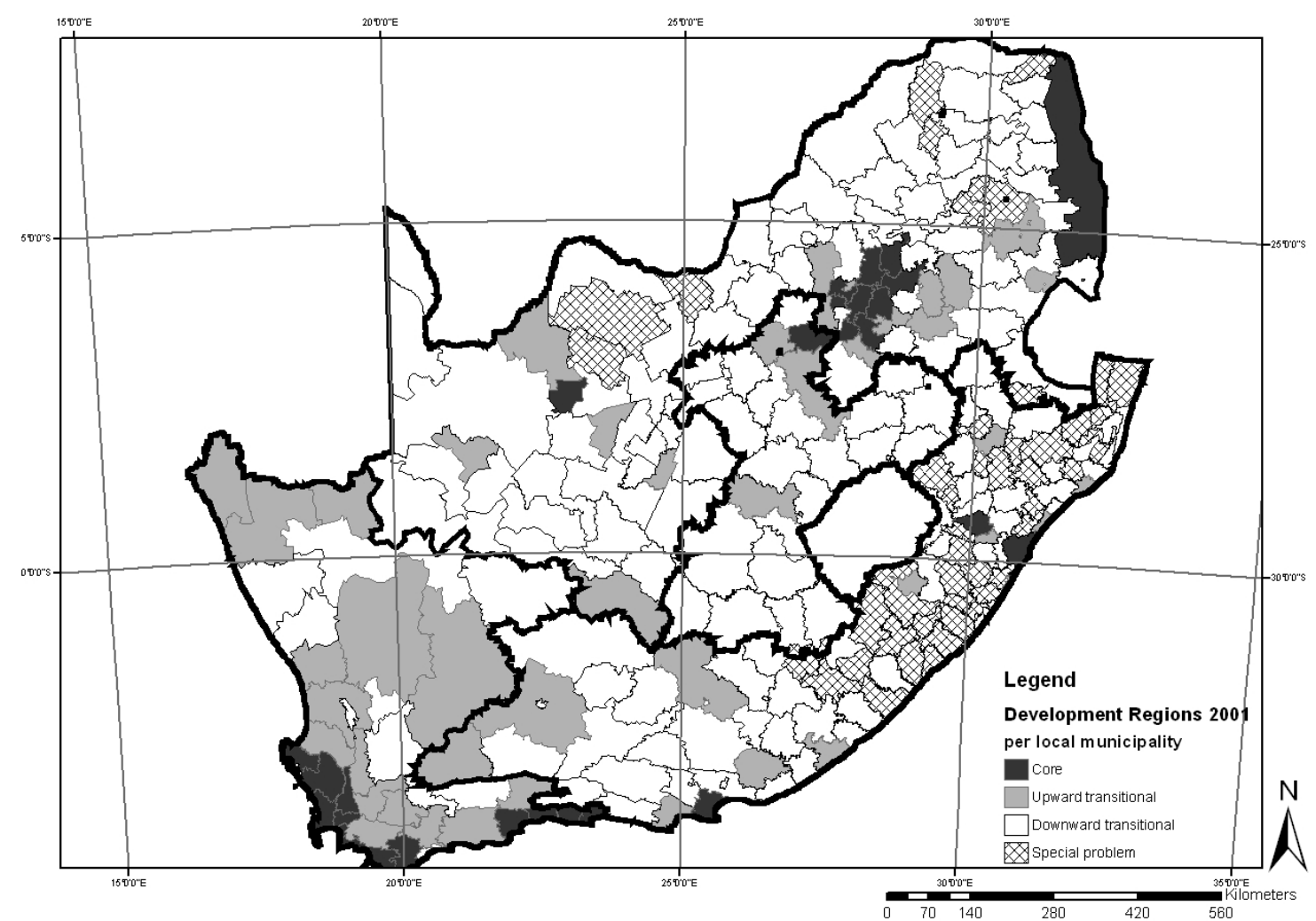

Figure 11: Development regions in the South African space economy, with the four proposed provinces superimposed on the development regions.

\subsection{Socio-economic results, using 2001 Census data}

The last five provinces are finally compared using certain socio-economic variables of data extracted from the Census 2001 Community Profile Databases [23]. The Limpopo Province region is kept separate from the Gauteng/North West region, because it was noticed that the combined region comprised $47.7 \%$ of the country, and might be too large to be considered a province. The results in Tables 5,6 and 7 were calculated by weighing the data in the main places appropriately.

The weighted mean and median values for each region might differ substantially, because of the uneven distribution of the variables amongst the different main places within each 
region. For this reason, both statistics are reflected.

The statistics in Table 5 were weighted for the total number of people in each main place. The Western Cape region has the highest level of urbanisation (795 per 1000 persons), followed by the Free State / North West and Gauteng / North West regions (approximately 630 per 1000 persons). The Limpopo region has the lowest number (165 per 1000 persons), the lowest number of informal persons, too, but the highest level of tribal / farm / small holding persons (785 per 1000 persons) and the highest level of youthful dependency (children 0-14 years of age). The other regions have approximately the same level of informal persons (between 77 and 93 per 1000 persons). The Western Cape has the lowest level of tribal / farm / small holding persons per 1000 persons.

The statistics in Table 6 were weighted for the number of persons between 15 and 65 years of age. The Western Cape region has the highest level of agricultural and manufacturing activity and the highest employment level per 1000 people aged 15 to 65 years, but the lowest level of mining activities. This region has the lowest number of people with education level of grade 7 and lower per 1000 people aged 15 to 65 years.

The Free State / North West region has a high level of agricultural and mining activity, but low on the manufacturing level per 1000 people aged 15 to 65 years of age. Employment levels are average.

\begin{tabular}{|c|c|c|c|c|c|c|}
\hline $\begin{array}{l}\text { Province } \\
\text { (number of } \\
\text { main places) }\end{array}$ & $\begin{array}{c}\% \text { of the total } \\
\text { number of } \\
\text { people in } \mathrm{SA}\end{array}$ & & $\begin{array}{l}\text { Urban } \\
\text { Person }\end{array}$ & $\begin{array}{l}\text { Informal } \\
\text { Person }\end{array}$ & $\begin{array}{l}\text { Tribal + farm } \\
\text { small holding }\end{array}$ & $\begin{array}{l}\text { Youthful } \\
\text { dependency }\end{array}$ \\
\hline Western Cape & & WMN: & 795 [A] & $78[\mathbf{A}]$ & 98 [D] & 273 [D] \\
\hline region & & WMD: & 929 & 5 & 0 & 279 \\
\hline$(350)$ & 10.2 & WQ: & $733-968$ & $0-112$ & $0-12$ & $246-300$ \\
\hline Free State/North & & WMN: & $632[\mathbf{B}]$ & $77[\mathbf{A}]$ & $258[\mathbf{C}]$ & $305[\mathbf{C}]$ \\
\hline West region & & WMD: & 810 & 0 & 0 & 314 \\
\hline$(267)$ & 7.20 & WQ: & 0-963 & $0-171$ & $0-843$ & $282-338$ \\
\hline Eastern Cape/ & & WMN: & $333[\mathbf{C}]$ & $92[\mathbf{A}]$ & $554[\mathrm{~B}]$ & $355[\mathrm{~B}]$ \\
\hline KwaZulu-Natal & & WMD: & 0 & 0 & 964 & 351 \\
\hline region (1288) & 34.9 & WQ: & $0-809$ & $0-103$ & 0-999 & $284-434$ \\
\hline Gauteng/North & & WMN: & $635[\mathrm{~B}]$ & $93[\mathbf{A}]$ & $239[\mathbf{C}]$ & $269[\mathrm{D}]$ \\
\hline West region & & WMD: & 846 & 34 & 0 & 257 \\
\hline$(627)$ & 31.0 & WQ: & $338-899$ & $0-93$ & $0-137$ & $216-310$ \\
\hline Limpopo & & WMN: & $165[\mathrm{D}]$ & $30[\mathbf{B}]$ & $785[\mathbf{A}]$ & $379[\mathbf{A}]$ \\
\hline region & & WMD: & 0 & 0 & 992 & 407 \\
\hline$(496)$ & 16.7 & WQ: & $0-0$ & $0-0$ & $957-999$ & $341-424$ \\
\hline South & & WMN: & 467 & 80 & 427 & 320 \\
\hline Africa & & WMD: & 659 & 0 & 12 & 250 \\
\hline (3028) & 100 & WQ: & 0-893 & 0-92 & 0-994 & $397-317$ \\
\hline
\end{tabular}

Table 5: Comparing the five intramax regions with respect to area of residence and youthful dependency per 1000 persons. [A] to [D]: different symbols indicate which means of these variables (comparing different regions in descending order from $[A]$ to $[D]$ ) are significantly different, Bonferroni multiple comparison test, $p<0.05$. The following abbreviations are used: WMN for weighted mean per 1000 persons, WMD for weighted median per 1000 persons and WQ for weighted inter-quartile range per 1000 persons. 
The Eastern Cape / KwaZulu-Natal region features significantly less agricultural activity, less mining activities, the lowest level of employment, and comparatively a high level of people with an education level of grade 7 and lower. However, some manufacturing activities take place in this region.

The Gauteng / North West region has a low level of agricultural activity, a high level of mining activity and a relatively high level of manufacturing activity and employment compared to the other regions.

The Limpopo region has a high level of agricultural activity, a higher than average level of mining activity, but a low level of manufacturing activity and a low level of employment. If combined with the Gauteng / North West region, the two regions can augment each other.

\begin{tabular}{lrlllll}
\hline $\begin{array}{l}\text { Province (number } \\
\text { of main places) }\end{array}$ & & $\begin{array}{l}\text { Industry } \\
\text { agriculture }\end{array}$ & $\begin{array}{l}\text { Industry } \\
\text { mining }\end{array}$ & $\begin{array}{l}\text { Industry } \\
\text { manufacturing }\end{array}$ & Employed & $\begin{array}{l}\text { Grade } 7 \\
\text { and less }\end{array}$ \\
\hline Western & WMN: & $67[\mathbf{A}]$ & $3.4[\mathbf{C}]$ & $67[\mathbf{A}]$ & $484[\mathbf{A}]$ & $272[\mathbf{C}]$ \\
Cape region & WMD: & 9 & 1.0 & 75 & 489 & 254 \\
(348) & WQ: & $7-30$ & $0-2$ & $34-91$ & $9425-526$ & $178-312$ \\
Free State/ & WMN: & $55[\mathbf{A}]$ & $34[\mathbf{A}]$ & $24[\mathbf{D}]$ & $337[\mathbf{C}]$ & $420[\mathbf{A}]$ \\
North West & WMD: & 8 & 2 & 21 & 290 & 428 \\
region (267) & WQ: & $5-18$ & $1-18$ & $10-30$ & $0226-483$ & $360-502$ \\
Eastern Cape/ & WMN: & $23[\mathbf{B}]$ & $1[\mathbf{C}]$ & $38[\mathbf{C}]$ & $251[\mathbf{D}]$ & $418[\mathbf{A}]$ \\
KwaZulu-Natal & WMD: & 4 & 1 & 27 & 228 & 424 \\
region (1287) & WQ: & $3-9$ & $0-2$ & $4-60$ & $93-378$ & $269-570$ \\
Gauteng/ & WMN: & $22[\mathbf{B}]$ & $23[\mathbf{A B}]$ & $51[\mathbf{B}]$ & $404[\mathbf{B}]$ & $303[\mathbf{B}]$ \\
North West & WMD: & 6 & 3 & 50 & 352 & 283 \\
region (627) & WQ: & $4-10$ & $2-7$ & $30-66$ & $287-541$ & $169-403$ \\
Limpopo & WMN: & $51[\mathbf{A}]$ & $15[\mathbf{B}]$ & $24[\mathbf{D}]$ & $270[\mathbf{D}]$ & $445[\mathbf{A}]$ \\
region & WMD: & 11 & 2 & 14 & 214 & 462 \\
(496) & WQ: & $6-21$ & $1-9$ & $6-31$ & $123-354$ & $394-521$ \\
South & WMN: & 34 & 13 & 43 & 337 & 367 \\
Africa & WMD: & 7 & 2 & 38 & 322 & 360 \\
(3025) & WQ: & $4-13$ & $1-4$ & $11-63$ & $189-497$ & $228-500$ \\
\hline
\end{tabular}

Table 6: Comparing the five intramax regions with respect to industries, employment and education per 1000 of persons aged 15-65. [A] to [D]: different symbols indicate which means of these variables (comparing different regions in descending order from $[A]$ to $[D]$ ) are significantly different, Bonferroni multiple comparison test, $p<0.05$. The following abbreviations are used: WMN for weighted mean per 1000 persons (aged 15-65), WMD for weighted median per 1000 persons (aged 15-65) and WQ for weighted inter-quartile range per 1000 persons (aged 15-65).

The statistics in Table 7 were weighted for the total number of households. The Western Cape region has the highest level of annual household income, and the highest mean number of households living in brick houses, equipped with electricity and piped water inside the house per 1000 households. The Free State / North West region has the highest level of informal houses per 1000 households. The Eastern Cape / KwaZulu-Natal region has the lowest level of brick housing, and the lowest level of electricity and piped water in the house per 1000 households. The Limpopo region has the lowest level of annual household income. 


\begin{tabular}{lrlllll}
\hline $\begin{array}{l}\text { Province (number } \\
\text { of main places) }\end{array}$ & & $\begin{array}{l}\text { Ann hh } \\
\text { income }(\mathrm{R})\end{array}$ & $\begin{array}{l}\text { Brick } \\
\text { house }\end{array}$ & $\begin{array}{l}\text { Informal } \\
\text { house }\end{array}$ & $\begin{array}{l}\text { Elec- } \\
\text { tricity }\end{array}$ & $\begin{array}{l}\text { Piped water } \\
\text { in house }\end{array}$ \\
\hline Western & WMN: & $75615[\mathbf{A}]$ & $631[\mathbf{A}]$ & $156[\mathbf{B}]$ & $878[\mathbf{A}]$ & $851[\mathbf{A}]$ \\
Cape region & WMD: & 63850 & 606 & 53 & 929 & 931 \\
$(344)$ & WQ: & $408-116$ & $558-773$ & $37-217$ & $814-984$ & $802-948$ \\
Free State/ & WMN: & $30853[\mathbf{C}]$ & $572[\mathbf{B}]$ & $232[\mathbf{A}]$ & $747[\mathbf{B}]$ & $699[\mathbf{C}]$ \\
North West & WMD: & 18610 & 594 & 231 & 748 & 663 \\
region (266) & WQ: & $13926-28160$ & $465-669$ & $43-356$ & $638-879$ & $585-914$ \\
Eastern Cape/ & WMN: & $34123[\mathbf{C}]$ & $413[\mathbf{C}]$ & $106[\mathbf{C}]$ & $573[\mathbf{D}]$ & $458[\mathbf{D}]$ \\
KwaZulu-Natal & WMD: & 19896 & 429 & 41 & 645 & 516 \\
region (1282) & WQ: & $13955-36424$ & $204-568$ & $13-131$ & $5299-859$ & $46-820$ \\
Gauteng/ & WMN: & $60780[\mathbf{B}]$ & $555[\mathbf{B}]$ & $211[\mathbf{A}]$ & $787[\mathbf{B}]$ & $754[\mathbf{B}]$ \\
North West & WMD: & 29916 & 558 & 147 & 853 & 856 \\
region (626) & WQ: & $20738-101675$ & $437-676$ & $51-327$ & $698-916$ & $684-911$ \\
Limpopo & WMN: & $26135[\mathbf{C}]$ & $624[\mathbf{A}]$ & $89[\mathbf{C}]$ & $629[\mathbf{C}]$ & $467[\mathbf{D}]$ \\
region & WMD: & 17642 & 673 & 42 & 649 & 415 \\
(491) & WQ: & $13787-22741$ & $479-777$ & $17-89$ & $510-773$ & $249-689$ \\
South & WMN: & 46361 & 530 & 155 & 702 & 623 \\
Africa & WMD: & 23954 & 558 & 82 & 763 & 731 \\
(3009) & WQ: & $16190-56298$ & $411-682$ & $23-243$ & $581-903$ & $384-886$ \\
\hline
\end{tabular}

Table 7: Comparing the five intramax regions with regards to household income, type of housing and services per 1000 of households. [A] to [D]: different symbols indicate which means of these variables (comparing different regions in descending order from $[A]$ to $[D]$ ) are significantly different, Bonferroni multiple comparison test, $p<0.05$. The following abbreviations are used: $W M N$ for weighted mean per 1000 households, WMD for weighted median per 1000 households and $W Q$ for weighted inter-quartile range per 1000 households.

\section{Conclusion}

Based on journey-to-work flows extracted from Census 2001 data, the intramax procedure was used to aggregate the 3109 (with some minor modifications) main places in South Africa into four or possibly five provinces. The provinces thus identified are:

- A 'Western Cape' province, which includes most of the current Western Cape and some regions of the previous Northern Cape region;

- a coastal province which is the amalgamation of most regions in the Eastern Cape and KwaZulu-Natal provinces;

- a central province consisting of most of the Free State and a small part of the North West province;

- a combination of the Gauteng province, the remainder of the Northern Cape and North West province; and

- a combination of the Limpopo province and the Northern parts of Mpumalanga.

It is interesting to note that provinces with relatively low commuting figures, as reflected in Table 3, also have low employment figures, as reflected in Table 6.

Disputed areas were highlighted and intramax solutions were provided for these disputes. These solutions are based on economic activities of people living in the areas, which might be of interest to policy makers in future. 
The results of a recent paper on the demarcation of the socio-economic development regions in the South African space economy were discussed with the purpose of applying them to the newly formed provinces. It is clear that the Western Cape region, with a strong core and mostly upward transitional regions also reflects high socio-development, according to Tables 5-7. The Eastern Cape / KwaZulu-Natal region reflects three minor core regions and large downward transitional and special problem regions. This is reflected in the fact that the socio-economic variables in Tables 5-7 clearly indicate that few industrial activities take place (apart from manufacturing). This region also suffers from low education, employment and income levels and poorly developed services in comparison with the other provinces. The development of this region poses a challenge to the government, but it has a true potential to improve, especially given its manufacturing base and access to harbours.

The central region, comprising of a combination of most of the Free State and parts of the North West province is almost a perfect match. The agricultural industry in the Free State combined with some mining activities from the regions in the North West province ensures that this region can be economically viable. Additionally, the fact that there are no problem regions according to the South African space economy model, indicates that this region can be economically independent.

The last two regions - Gauteng, parts of the Northern Cape, the North West province and a combination of Limpopo and Mpumalanga - may be too large for one province, but the northern region has no core (the Kruger Park should be seen independently), large problem areas and downward transitional regions, which correspond to low income, poor education and employment levels compared to the other regions with large rural areas. It has a good agricultural industry in place, as well as some mining activities, which might be further explored. If this province is combined with the highly developed Gauteng region, which lacks a significant agricultural industry, it can be a powerful region.

Based on commuting flows, the intramax method is a useful tool for demarcating regions using daily activity systems. From a management point of view provincial/adminstrative boundaries should take these daily activity systems into account in some form or another.

\section{References}

[1] Brown LA \& Holmes J, 1971, The delimitation of functional regions, nodal regions, and hierarchies by functional distance approaches, Journal of Regional Science, 11(1), pp. 57-72.

[2] Brown PJB \& Pitfield DE , 1990, An intramax derivation of commodity market areas from freight flow data, Transportation Planning and Technology, 15, pp. 59-81.

[3] Cross-boundary Municipalities Laws Repeal and Related Matters Act of 2005, South Africa, [Statute], Government Gazette, 486, Pretoria, pp. 1-20.

[4] Feldman O, Simmonds D, Troll N \& Tsang F, 2005, Creation of a system of functional areas for England and Wales and for Scotland. Proceedings of the European Transport Conference, [Online], [cited 2008, August 11], Available from: http://www.mvaconsultancy.com/papers/Creation $\% 20$ of $\% 20$ a $\% 20$ system $\% 20$ of $\% 20$ functional $\% 20$ areas $\% 20$ for $\% 20$ England $\% 20$ and $\% 20 W \% 85$.pdf

[5] Fischer MM, Essletzbichler J, Gassler H \& Trichtl G, 1993, Telephone communication patterns in Austria: A comparison of the IPFP-based graph-theoretic and the intramax approaches, Geographical Analysis, 25(3), pp. 224-233. 
[6] Floor J \& De Jong T, 1981, Development and testing of a residential location model, PhD Dissertation, Utrecht University, Utrecht.

[7] Goodman L, 1963, Statistical methods for the preliminary analysis of transaction flows, Econometrica, 31, pp. 197-208.

[8] Greater Sekhukhune District Municipality, 2008, Integrated development plan: 2007/2008 review, [Online], [cited 2008, August 11], Avialable from: http://www.sekhukhune.gov.za/2007-08\%20 FINAL\%20IDP.pdf

[9] Griggs RA, 1998, The security costs of party-political boundary demarcations: The case of South Africa, African Security Review, 7(2), pp. 22-32.

[10] Harmse AC, 2007, Socio-economic development regions in the South African space economy, The South African Geographical Journal, 89, pp. 83-88.

[11] Harmse AC, BlaAuw PF \& SChenck CJ, 2008, Day labourers, unemployment and socio-economic development in South Africa, Working Paper Number 69, Department of Geography, University of South Africa, Pretoria.

[12] Hirst MA, 1977, Hierarchical aggregation procedures for interaction data: A comment, Environment and Planning A, 9, pp. 99-103.

[13] Hollingworth TH, 1971, Gross migration flows as a basis for regional definition: An experiment with Scottish data, Proceedings of the IUSSP Conference held in London in 1969, 4, pp. 2755-2765.

[14] Masser I \& Brown PJB, 1975, Hierarchical aggregation procedures for interaction data, Environment and Planning A, 7, pp. 509-523.

[15] Masser I \& SCheurwater J, 1980, Functional regionalization of spatial interaction data: An evaluation of some suggested strategies, Environment and Planning A, 12, pp. 1357-1382.

[16] Mavungu EM, 2007, Explaining boundary disputes in post-apartheid South Africa: Bushbuckridge, Matatiele and Khutsong, University of the Witwatersrand, Johannesburg, Newsroom, 23 October 2007, [Online], [cited 2008, August 11], Available from: http://web.wits.ac.za/NewsRoom/NewsItems/khutsong.htm

[17] Mitchell W, Bill A \& Watts M, 2007, Identifying functional regions in Australia using hierarchical aggregation techniques, Working Paper No. 07-06, Centre of Full Employment and Equity, The University of Newcastle, Callaghan (Australia).

[18] Ngalwa S, 2007, Review of number of provinces under way, The Star, pp. 6, 20 June 2007.

[19] Ramutsindela MF \& Simon D, 1999, The politics of territory and place in post-apartheid South Africa: The disputed area of Bushbuckridge, Journal of Southern African Studies, 25(3), pp. 479-498.

[20] Slater PB, 1975, A hierarchical regionalization of Japanese prefectures using 1972 interprefectural migration flows, Regional Studies, 10, pp. 123-132.

[21] Smith A, 2007, Four provinces mooted for SA, Die Burger, 3 May 2007, [Online], [cited 2008, August 11], Available from: http://www.news24.com/News24/South_Africa/Politics/ 0, , 2-7-12_2107703,00.html

[22] Statistics South Africa, 2001, Census 2001, Subdatabase compiled from community profile databases by Statistics South Africa, Pretoria.

[23] Statistics South Africa, 2001, Census 2001, Community profile databases, Available from: http://www.statssa.gov.za/census01/html/C2001CommProfile.asp.

[24] Tyree A, 1973, Mobility ratios and association in mobility tables, Population Studies, 27, pp. 577588.

[25] Van der Zwan J, Van der Wel R, Ritsema van Eck J, De Jong T \& Floor H, 2003, FLOWMAP \%. Manual, Faculty of Geographical Sciences, Utrecht University, Utrecht.

[26] WARD JH, 1963, Hierarchical grouping to optimize an objective function, Journal of the American Statistical Association, 58(301), pp. 236-244. 